\title{
Herpes Simplex Virus Type 2 Infections Presenting as Brainstem Encephalitis and Recurrent Myelitis
}

\author{
Hideto NaKajima, Daisuke Furutama, Fumiharu Kimura, Keiichi Shinoda, \\ Toshimasa NAKAGAWA*, Akira SHIMIZU* and Nakaaki OHSAWA
}

\begin{abstract}
We describe here 3 patients with central nervous system infection caused by herpes simplex virus type 2 (HSV-2); one patient with brainstem encephalitis and two with recurrent transverse thoracic myelitis. All three patients showed increased IgG antibodies to HSV in the cerebrospinal fluid (CSF). HSV-2 DNA was demonstrated in the CSF by polymerase chain reaction (PCR) amplification. Upon treatment with acyclovir, one patient with myelitis partially recovered and the others completely recovered. It is important to recognize the wide spectrum of clinical manifestations of HSV-2 infection in the central nervous system (CNS).
\end{abstract}

(Internal Medicine 34: 839-842, 1995)

Key words: polymerase chain reaction, central nervous system, cerebrospinal fluid

\section{Introduction}

Herpes simplex virus (HSV) is one of the main pathogens causing encephalomyelitis. The clinical manifestations of HSV infection in the central nervous system (CNS) are classified into three types; encephalitis, brainstem encephalitis, and myelitis. The HSV encephalitis predominantly affects the limbic system and the adjacent areas of the frontotemporal lobe. A diagnosis for HSV encephalitis can be made with magnetic resonance imaging (MRI), electroencephalography (EEG) and biopsy. Although the HSV encephalitis is considered to be caused mainly by HSV type 1 (HSV-1), some cases of HSV type 2 (HSV-2) encephalitis have been reported recently (1). HSV brainstem encephalitis has also been documented, of which the diagnosis, however, is based on clinical manifestations such as cranial nerve palsy, cerebellar ataxia and conscious disturbances, and elevated titers of anti-HSV antibodies or isolation of HSV from cerebrospinal fluid (CSF) (2-9). It is unknown which type of HSV causes brainstem encephalitis. HSV myelitis is a serious disorder presenting with an ascending necrotizing myelitis (10-18). It was considered in an autopsy specimen study that HSV-2 mainly causes myelitis. Most patients with HSV encephalomyelitis present a monophasic course. However, patients with recurrent HSV encephalomyelitis have been increasing owing to the advances in diagnostic assays, including the polymerase chain reaction (PCR) technique $(19,20)$. Here we describe a patient with brainstem encephalitis and two patients with recurrent myelitis due to HSV-2, and in whom the diagnosis was confirmed by PCR analysis of CSF.

\section{Case Report}

\section{Patient 1}

A 67-year-old male, previously healthy, was admitted to our hospital because of walking difficulties, facial palsy, and headaches following a 5-day episode of fever $\left(37.0^{\circ} \mathrm{C}\right)$. No skin nor mucosal rashes were noted, and no abnormalities were found on general examination. Blood pressure was 120/80 $\mathrm{mmHg}$, pulse rate 78 beats per minute, and temperature was $36.0^{\circ} \mathrm{C}$. He was alert, but had nuchal stiffness. Optic fundi, pupils, and ocular movements were normal. We observed horizontal nystagmus on lateral gaze, hypesthesia on the left half of the face, and left facial nerve palsy of the peripheral type. Weakness or sensory disturbance were not found on the trunk and extremities. The deep reflexes were normal, but Babinski's sign was positive on the right. He showed truncal oscillation, and his gait was wide-based.

Routine blood chemistry was normal. CSF analysis showed 240 white blood cells (WBC) (98\% mononuclear cells), protein value of $132 \mathrm{mg} / \mathrm{dl}, \mathrm{IgG}$ index of 0.77 , myelin basic protein of $3.1 \mu \mathrm{g} / \mathrm{ml}$, and negative oligoclonal IgG bands. Brain MRI showed no abnormalities even with Gd-DTPA (gadliniumdiethylenetriamine pentaacetic acid) enhancement. Electroencephalogram and somatosensory evoked potential were nor-

From the First Department of Internal Medicine and *the Department of Clinical Pathology, Osaka Medical College, Osaka

Received for publication November 8, 1994; Accepted for publication May 12, 1995

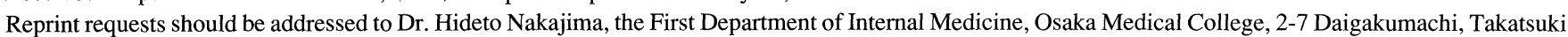
569 
mal. Viral titers, including HSV-1, HSV-2, herpes-zoster virus (HZV), Epstein-Barr virus (EBV), and human T lymphotropic virus type I (HTLV-I) were measured by enzyme immunoassay (EIA) and neutralization test (NT). HSV-1 (NT), HSV-2 (NT), HSV-1 IgG (EIA), HZV IgG (EIA), and EBV IgG (EIA) were present in his serum. In CSF, HSV-1 IgG was also positive (capture EIA index 0.399), while HSV-1 (NT) and HSV-2 (NT) were negative. He was treated with acyclovir $(1,500 \mathrm{mg} /$ day $)$ and betamethasone $(12 \mathrm{mg} /$ day) for 14 days, and recovered gradually. Two months after his admission, he regained ability to walk without help. At repeated CSF examinations, the total protein level had gradually declined to the normal range, and the HSV antibody titer was still positive (capture EIA index 0.368).

\section{Patient 2}

A 49-year-old female presented with urinary retention, back pain, numbness and a sudden onset of weakness in both legs. Neurological examination showed paraparesis, positive Babinski sign, and sensory disturbances below the T-5 level on the right and below the T-7 level on the left. The urodynamic study showed atonic contraction. Analysis of her CSF showed 30 WBC (all mononuclear cells), protein of $79 \mathrm{mg} / \mathrm{dl}, \mathrm{IgG}$ index of 0.32 , myelin basic protein of $3.1 \mu \mathrm{g} / \mathrm{ml}$, and an absence of oligoclonal IgG bands. A myelogram revealed cord enlargement at the levels of T-3 to T-7 segments. Anti-HSV antibody by EIA was positive in her CSF. After treatment with intravenous acyclovir $(1,500 \mathrm{mg} /$ day $)$ and betamethasone $(8 \mathrm{mg} /$ day $)$ for 4 weeks, she recovered significantly. One year and 10 months later, she again developed myelopathy at the T-6 level, and she showed Romberg's sign. CSF analysis showed 196 WBC (100\% mononuclear cells), protein of $90 \mathrm{mg} / \mathrm{dl}, \mathrm{IgG}$ index of 0.51 , and myelin basic protein of $6.7 \mu \mathrm{g} / \mathrm{ml}$. MRI of her thoracic cord indicated an increased signal intensity in the posterior portion of spinal cord at the 2nd thoracic vertebra on T1-weighted image with Gd-DTPA enhancement (Fig. 1). Brain MRI was normal. In her CSF, anti-HSV antibody using EIA remained positive. No herpetic vesicles were observed in either episodes. The test for serum antibody to human $T$ lymphotropic virus type I (HTLV-I) antibody and results of collagen vascular screening test were both negative. Flow cytometry showed no abnormality in lymphocyte subset. She was treated with acyclovir $(1,500 \mathrm{mg} /$ day $)$ and betamethasone $(8 \mathrm{mg} /$ day) for 3 weeks and again showed complete recovery.

\section{Patient 3}

A 38-year-old male presented with progressive weakness in both legs, urinary retention, and numbness, for one month. Neurological examination revealed paraparesis and sensory disturbances below the T-6 level. Babinski's sign was negative. His bladder was distended. Analysis of his CSF showed 11 WBC (all mononuclear cells), protein of $75 \mathrm{mg} / \mathrm{dl}, \mathrm{IgG}$ index of 0.44 , and a positive oligoclonal IgG band. The myelogram revealed the cord enlargement at the T- 2 to T- 6 segments. The anti-HSV-1 antibody in his CSF determined by immunofluorescence (IF) was 1:4, and in serum it was 1:640. After administration of intravenous acyclovir $(750 \mathrm{mg} /$ day for 4 weeks $)$ and

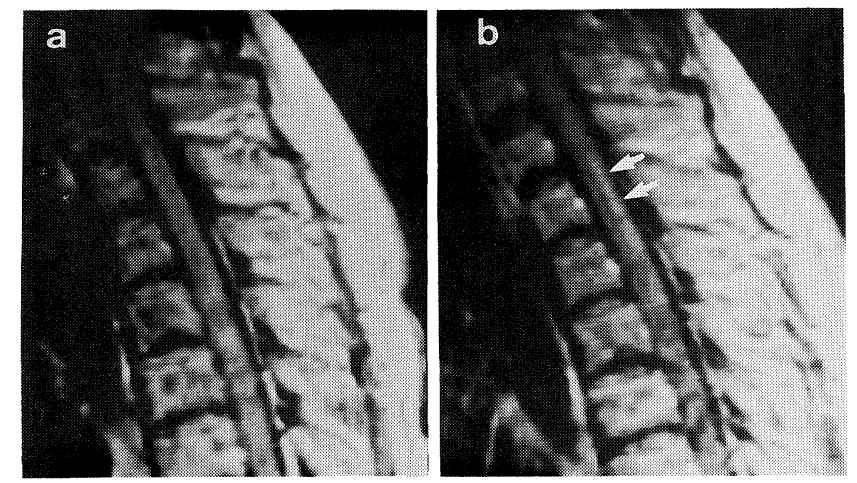

Figure 1. Unenhanced (a) and enhanced (b) sagittal MRI of Patient 2. During the second episode, MRI with Gd-DTPA enhancement showed an increased signal intensity in the posterior portion of the spinal cord at the 2nd thoracic vertebra (arrow) (TE 600, TR20).

prednisolone (60 mg/day for 2 weeks), his paraparesis improved. The anti-HSV-1 antibody in his CSF decreased 1:2, and serum antibody was 1:320. Five months later, however, myelopathy developed again at the same level. Analysis of his CSF showed $2 \mathrm{WBC}$ (all mononuclear cells), protein of $42 \mathrm{mg} / \mathrm{dl}$, $\mathrm{IgG}$ index of 0.25 , and negative oligoclonal IgG bands. Brain and thoracic MRI showed no abnormalities. The anti-HSV-1 antibody (IF) in his CSF was 1:8, and serum antibody was $1: 1,280$. Serum antibody against HTLV-I was negative. Intravenous methylprednisolone ( $1 \mathrm{~g} /$ day for 3 days) exerted beneficial effects. During the second episode genital herpetic vesicles were observed, and antibody to HSV remained positive in the CSF. He was then administered intravenous acyclovir ( $750 \mathrm{mg} /$ day for 4 weeks), with improvement in numbness and urinary retention, but the paraparesis persisted.

\section{Polymerase chain reaction}

The serial CSF samples in the present patients were applied to PCR amplification. For DNA preparation, $500 \mu 1$ of CSF was treated at $55^{\circ} \mathrm{C}$ for 6 hours in lysis buffer containing $0.6 \%$ SDS, $10 \mathrm{mM}$ TRIS, $10 \mathrm{mM}$ EDTA and $1 \mathrm{mg} / \mathrm{ml}$ proteinase $\mathrm{K}$. The DNA was phenol-chloroform extracted and precipitated with ethanol.

The primer sequences were chosen to flank a conserved region in the HSV-1 and HSV-2 DNA polymerase gene. The primers used in the first PCR were as follows: 5'-CAGTACGGCCCCGAGTTCGTGACCGGG-3' and 5'-TACTCGCCGATCACCCCGCG-3'. For the nested PCR, 5'-CATCATCAACTTCGACTGGCCC-3' and 5'-GGCGTAGTAGGCGGGGATGTCGCG-3' were constructed as the inner primer pair within the previous one. On the first round of PCR, the cycles consisted of DNA denaturation at $94^{\circ} \mathrm{C}$ for 1 minute, primer annealing at $60^{\circ} \mathrm{C}$ for 1 minute and primer extension at $72^{\circ} \mathrm{C}$ for 1 minute for 35 cycles. On the second round of PCR, $1 \mu \mathrm{l}$ of the first PCR products were applied with $49 \mu \mathrm{l}$ of a freshly prepared reaction mixture, followed by 30 cycles of 
a

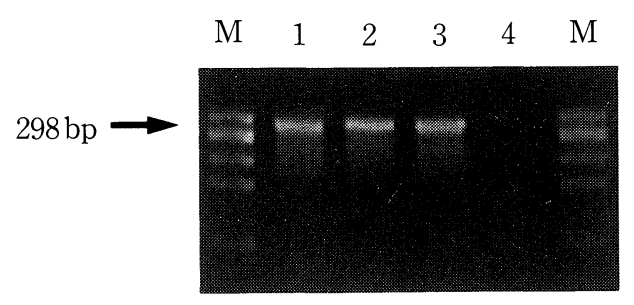

b

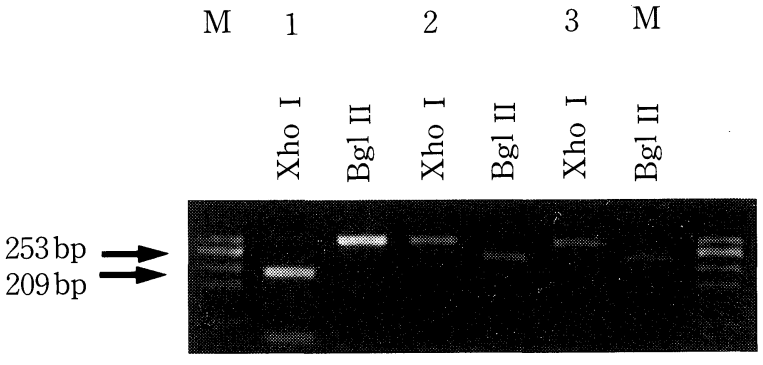

Figure 2. a) Agarose gel electrophoresis shows PCR amplified products of HSV-1 and HSV-2 strains at a sequence of $298 \mathrm{bp}$. b) A specific recognition sequence for $\mathrm{Xho} I$ restriction enzyme is only present in HSV-1 DNA, and for Bgl II restriction enzyme only in HSV-2 DNA. Xho I yields 209bp and $89 \mathrm{bp}$ fragments for HSV1, whereas Bgl II yields $45 \mathrm{bp}$ and $253 \mathrm{bp}$ fragments for HSV-2. (1) HSV-1 strain; (2) HSV-2 strain; (3) CSF sample from Patient1 with HSV-2 brainstem encephalitis; (4) CSF sample from negative control. (M): molecular weight makers (Hae III digest of $\emptyset \times 174$ ).

amplification with $95^{\circ} \mathrm{C}$ for 30 seconds, $60^{\circ} \mathrm{C}$ for 30 seconds, and $72^{\circ} \mathrm{C}$ for 30 seconds. When HSV-1 or HSV-2 DNA existed in the mixture, a 298-bp sequence was amplified by the nested PCR. Within this sequence, individual virus strains have unique restriction sites so that amplification products could be typed by digestion with Bgl II and Xho I (Fig. 2). The PCR assay showed the presence of HSV-2 DNA in CSF samples from all 3 patients, and revealed no HSV-1 DNA. In the two cases of recurrent myelitis, HSV-2 DNA was detected in the CSF at the first and second attacks. As controls, we tested the CSF samples from 16 patients ( $5 \mathrm{MS}, 1$ viral myelitis, 4 aseptic meningitis, 3 CIDP, 3 AIDP). No HSV-1 DNA nor HSV-2 DNA was detected in any of these samples.

\section{Discussion}

As a clinical manifestation of HSV-2 infection in the CNS, various syndromes have been reported such as encephalitis, meningitis, and myelitis. HSV-2 encephalitis typically occurs in the newborn, whereas herpetic encephalitis in the adult is mainly caused by HSV-1. Herpetic meningitis and myelitis are found in adults with HSV-2 genitalitis. Since the first report of HSV brainstem encephalitis (HSBE) by Dayan et al (2), HSV infection has been recognized as one of the important causative pathogens in adult brainstem encephalitis $(3-9,19)$. To the best of our knowledge, previous reported cases of HSBE were diagnosed by detection of HSV antigens in the cell from the CSF (2), isolation of the virus from autopsied specimens $(2,7$, 8 ), and a rise in antibody titers $(2-6,9)$. Although CSF cultures generally provide a reliable diagnosis for etiological pathogens in those patients, many attempts to isolate HSV from the CSF have been unsuccessful even in those patients having HSBE finally confirmed at autopsy $(2,8)$. The poor sensitivity of viral culture in CSF suggests the predominant presence of the virus within the nervous tissue but not in the surrounding CSF. With virus typing in brainstem encephalitis, Lach and Atack (8) proved HSV-1 in autopsy specimens using immunohistochemical typing, while the other reported cases did not perform typing of HSV (2-7, 9). Mertens et al (19) detected HSV-1 DNA in the CSF obtained from a patient with $\mathrm{HSBE}$ using the PCR method. This is the first report to demonstrate a HSBE patient with HSV2.

HSV involvement in the spinal cord is also recognized as ascending myelitis since the first case of HSV myelitis reported by Klastersky et al (10), in which they could prove HSV etiology by isolating HSV-1 from the CSF. In previous reports, HSV myelitis was often presented as ascending myelitis, and occurred in association with immunocompromised states, such as $\operatorname{AIDS}(11,12)$, malignancy $(13,14)$ and diabetes mellitus $(15,16)$. Recently, Ellie et al (17) and Flope et al (18) reported acute necrotizing myelitis caused by HSV-2 in nonimmunocompromised patients. HSV myelitis was fatal and monophasic disorder, and the diagnosis could only be made at autopsy in all but one case. Ahmed (21) described HSV-2 myelitis with a favorable outcome, diagnosed by isolating viruses from the CSF. Shyu et al (20) could detect HSV-1 DNA in the CSF obtained from a 72-year-old woman with recurrent myelopathy whose clinical course and findings were similar to the presented Patient 2.

Whether HSV-2 spreads to the CNS by a neuronal or a hematogenous route has been discussed. Both HSV-1 and HSV-2 are known to establish a latent infection, generally in the cranial nerve ganglia and spinal dorsal root ganglia. In HSV-2 myelitis, a neural spread into the spinal cord is proposed to occur by the induction of reactivation of a latent infection within the dorsal root ganglia (15). The diagnosis of CNS-HSV infection is difficult because HSV is rarely isolated from CSF and the antibody against HSV is not always elevated during the early stage of this disease. And in brainstem encephalitis and myelitis, it is difficult to obtain a biopsy for accurate diagnosis. Current progression of PCR techniques provides clinical efficacy with rapid and sensitive diagnostic procedures $(1,22)$ Rowley et al (23) attempted to detect HSV DNA in CSF which was treated with ultracentrifugication. The CSF supernatant was positive for HSV DNA by PCR, however, the ultracontrifuged pellets gave negative results. This may indicate the presence of free viral DNA rather than intact viral particles. In the case of small amounts of HSV DNA in the CSF, PCR sensitivity becomes problem. In our method, the specificity and 


\section{NAKAJIMA et al}

the sensitivity of the PCR assay were enhanced through the two hybridization steps of the nested approach. The HSV infection in the CNS generally evidenced a poor outcome before the discovery of antiviral agents. Since acyclovir has become available for treatment, even in HSBE and HSV myelitis, a rapid and accurate confirmation is very important. It must be noted that there are diverse disease types of HSV-2 infection in the CNS.

Acknowledgements: We gratefully thank Dr. Masakuni Kameyama, the director of Sumitomo Hospital (Osaka), for his suggestions and his critical reading of this manuscript.

\section{References}

1) Aurelius E, Johansson B, Skoldenberg B, Forsgren M. Encephalitis in immunocompetent patients due to herpes simplex virus type 1 or 2 as determined by type specific polymerase chain reaction and antibody assay of cerebrospinal fluid. J Med Virol 39: 179, 1993.

2) Dayan AD, Goddy W, Harrison MJG, Rudge P. Brain stem encephalitis caused by herpes virus hominis. Br Med J 4: 405, 1972.

3) Fenton TR, Marshall PC, Cavamagh N, Wilson J, Marshall WC. Herpessimplex infection presenting as brainstem encephalitis. Lancet 2: 977, 1977.

4) Kindley $\mathrm{AD}$, Harris F, Bush GH. Herpes-simplex infection presenting as brainstem encephalitis. Lancet 1: 212, 1978.

5) Latronico N, Candiani A. Brainstem herpes virus encephalitis. Lancet 2: 690, 1987.

6) Patricia H, Ellison MD, Peggy A, Hanson MD. Herpes simplex: A possible cause of brainstem encephalitis. Pediatrics 59: 240, 1977.

7) Roman-Campos G, Toro G. Herpetic brainstem encephalitis. Neurology 30: $981,1980$.

8) Lach B, Atack E. Disseminated hemorrhagic leukoencephalomyelitis with localized herpes simplex brain stem infection. Acta Neuropathol 75: 354, 1988.

9) Martino GV, Grimaldi LM, Franciotta DM, et al. Isoelectric focusing herpes simplex virus-gB overlay study in brainstem encephalitis. Acta Neurol Scand 82: 364, 1990.
10) Klastersky J, Cappel R, Snoeck J, Flament J, Thiry L. Ascending myelitis in association with herpes simplex virus. N Engl J Med 287: 182, 1972.

11) Tucker T, Dix RD, Katzen C, Davis RL, Schimidley JW. Cytomegalovirus and herpes simplex virus ascending myelitis in a patient with acquired immune deficiency syndrome. Ann Neurol 18: 74, 1985.

12) Britton CB, Mesa-Tejada R, Fenoglio CM, Hays AP, Garvey GG, Miller JR. A new complication of AIDS: Thoracic myelitis caused by herpes simplex virus. Neurology 35: 1071, 1985.

13) Nakagawa $M$, Nakamura $A$, Kubota $R$, et al. Necrotizing myelopathy associated with malignancy caused by herpes simplex virus type 2 : Clinical report of two cases and literature review. Jpn J Med 30: 2, 1991.

14) Iwamasa $T$, Itsumi $Y$, Sakuda $H$. Two cases of necrotizing myelopathy associated with malignancy caused by herpes simplex virus type 2 . Acta Neuropathol (Berl) 78: 252, 1989.

15) Wiley CA, VanPatten PD, Carpenter PM, Powell HC, Thal LJ. Acute ascending necrotizing myelopathy caused by herpes simplex virus type 2 . Neurology 37: 1791, 1987.

16) Iwamasa $T$, Yoshitake H, Kamada $Y$, Miyazato M, Utsumi $Y$, Nakamura A. Acute ascending necrotizing myelitis in Okinawa caused by herpes simplex virus type 2. Virchows Archiv A Pathol Anat 418: 71, 1991.

17) Ellie E, Rozenberg F, Dousset $V$, Beylot-Barry M. Herpes simplex virus type 2 ascending myeloradiculitis: MRI findings and rapid diagnosis by the polymerase chain method. J Neurol Neurosurg Psychiatry 57: 869, 1994.

18) Flope A, Lapham LW, Smith HC. Herpes simplex myelitis as a cause of acute necrotizing myelopathy syndrome. Neurology 44: 1955, 1994.

19) Mertens G, Ieven M, Ursi D, Pattyn SR, Martin JJ, Parizel PM. Detection of herpes simplex virus in the cerebrospinal fluid of patients with encephalitis using the polymerase chain reaction. J Neurol Sci 118: 213, 1993.

20) Shyu WC, Lin JC, Chang BC, Harn HJ, Lee CC, Tsao WL. Recurrent ascending myelitis: an unusual presentation of herpes simplex virus type 1 infection. Ann Neurol 34: 625, 1993.

21) Ahmed I. Survival after herpes simplex virus type II myelitis. Neurology 38: $1500,1988$.

22) Ando $Y$, Kimura H, Miwata H, Kudo T, Shibata M, Morishima T. Quantitative analysis of herpes simplex virus DNA in cerebrospinal fluid of children with herpes simplex encephalitis. J Med Virol 41: 170, 1993.

23) Rowley AH, Whitley RJ, Lakeman FD, Wolinsky SM. Rapid detection of herpes simplex virus DNA in cerebrospinal fluid of patients with herpes simplex encephalitis. Lancet 335: 440, 1990. 